\title{
Integrated assessment of the spatial distribution and structural dynamics of deep benthic marine communities
}

\author{
Jan Jansen, ${ }^{1,6}$ Piers K. Dunstan, ${ }^{2}$ Nicole A. Hill, ${ }^{1}$ Philippe Koubbi,${ }^{3,4}$ Jessica Melbourne-Thomas, ${ }^{2}$ \\ Romain Causse, ${ }^{5}$ and Craig R. Johnson ${ }^{1}$ \\ ${ }^{1}$ Institute for Marine and Antarctic Studies (IMAS), University of Tasmania, 20 Castray Esplanade, Battery Point, Hobart, Tasmania \\ 7004 Australia \\ ${ }^{2}$ CSIRO Oceans and Atmosphere, Hobart, Tasmania, Australia \\ ${ }^{3}$ UFR 918 Terre Environnement Biodiversité, Sorbonne Université, Paris, France \\ ${ }^{4}$ Channel and North Sea Fisheries Research Unit, IFREMER, Boulogne-sur-Mer, France \\ ${ }^{5}$ Unité Biologie des Organismes et Ecosystèmes Aquatiques (BOREA), Muséum National d'Histoire Naturelle, Sorbonne Université, \\ Université de Caen Normandie, Université des Antilles, CNRS, IRD, Paris, France
}

Citation: Jansen, J., P. K. Dunstan, N. A. Hill, P. Koubbi, J. Melbourne-Thomas, R. Causse, and C. R. Johnson. 2020. Integrated assessment of the spatial distribution and structural dynamics of deep benthic marine communities. Ecological Applications 30(3):e02065. 10.1002/eap.2065

\begin{abstract}
Characterizing the spatial distribution and variation of species communities and validating these characteristics with data from the field are key elements for an ecosystem-based approach to management. However, models of species distributions that yield community structure are usually not linked to models of community dynamics, constraining understanding and management of the ecosystem, particularly in data-poor regions. Here we use a qualitative network model to predict changes in Antarctic benthic community structure between major marine habitats characterized largely by seafloor depth and slope, and use multivariate mixture models of species distributions to validate the community dynamics. We then assess how future increases in primary production associated with anticipated loss of sea-ice may affect the ecosystem. Our study shows how both spatial and structural features of ecosystems in data-poor regions can be analyzed and possible futures assessed, with direct relevance for ecosystem-based management.
\end{abstract}

Key words: Antarctica; continental shelf; deep sea; ecosystem dynamic; ecosystem structure; qualitative network model; Southern Ocean; spatial model; species archetype model; upper slope.

\section{INTRODUCTION}

Ecosystem-based management, which aims to conserve ecological services while simultaneously meeting socioeconomic, political, and cultural needs, is of key importance for sustainably managing natural resources now and into the future (Garcia et al. 2003). Fundamental to any ecosystem-based management is a thorough understanding of the functioning of the ecosystem of interest and the spatial distribution and composition of its major components. This is not an easy task and most approaches focus on only one aspect to the exclusion of the other. The two main pathways to gather this knowledge from collected data are models of community dynamics (either qualitative or quantitative) that focus on the ecological structure and functioning of the system and statistical models that spatially categorize distributions of species, functional groups, or other operational taxonomic units using their relationship to environmental predictor

Manuscript received 20 November 2018; revised 15 August 2019; accepted 11 November 2019. Corresponding Editor: Eric J. Ward.

${ }^{6}$ E-mail: jan.jansen@utas.edu.au variables. Combining statistical and qualitative models would allow us to understand both the composition and function of ecosystems.

Ecosystem models allow testing hypotheses regarding the dynamics of interaction networks and the potential impacts of external drivers on ecosystem components. They have been fundamental for the management and assessment of extractive industries (Dambacher et al. 2015, Marzloff et al. 2015, Harvey et al. 2016), in cumulative impact assessments (Melbourne-Thomas et al. 2011a, b, Anthony et al. 2013, Gurney et al. 2013), in evaluating food-webs (Gillies et al. 2013, MelbourneThomas et al. 2013, Heymans et al. 2016), and in predicting changes in ecosystem attributes under scenarios for human use and environmental change (Fulton 2010, Melbourne-Thomas et al. 2011a, b, Blanchard et al. 2017). These kinds of fully quantitative models usually require detailed information about the rates of physical and biological processes in the ecosystem. In contrast, spatial mapping of species distributions of ecosystems using statistical models, which typically underpin spatial planning including assessments for Marine Protected Areas (Barrett et al. 2001, Jordan et al. 2005, Hill et al. 2017), focus more on high-resolution predictions of the 
spatial distribution of distinct groups of species without considering the nonlinear correlations between species. A combination of both approaches allows complementary insight into ecosystems providing there is adequate validation by field data.

However, as the physical environment changes in space in both two and three dimensions, or through time, so do the interactions between the physical and the biological environment, influencing species distributions and ecosystem functioning (Edwards and Richardson 2004, Hoegh-Guldberg and Bruno 2010). This presents a challenge, particularly in data-limited regions where little is known about how biological communities function and how they change in space and through time, limiting the ability to both conserve the environment and ensure its sustainable use. Combining spatial and dynamic quantitative approaches could draw on the strengths of both, thereby clarifying potential biases and resolving areas of high agreement (Levins 1966, 1993). This approach could be useful for data-limited regions because simple network models can be developed using knowledge from similar ecosystems and then be combined with spatial data explicit to the region.

An environment that is comparatively little studied and not well understood is the deep ocean floor (here considered as anything below $200 \mathrm{~m}$ ), one of the largest biomes on Earth. To date, deep benthic and demersal ecosystems have usually been broadly categorized into shelf, slope, and abyssal habitats (O'Hara et al. 2011, Douglass et al. 2014, Woolley et al. 2016), with latitudinal gradients overlying species distributions (O'Hara et al. 2011, Woolley et al. 2013). However, the physical and ecological processes leading to the separation between these habitats and communities are not fully understood, and while species differ between the tropics, temperate, and polar regions, ecological theory suggest fundamental processes influencing their distribution should be similar (Woolley et al. 2016). Although depth, relief, rugosity, slope, and other features of the seafloor may not directly influence many species, they serve as a proxy for the important variables that do influence species distributions. In particular, these features of the seafloor determine whether the benthos at a particular location is characterized by hard or soft substrata, and they influence the local ocean current regime, food availability, and sedimentation patterns. Therefore, it is important to take into account seafloor features to understand how the structure and functioning of benthic ecosystems differ in space (Hogg et al. 2016, Jansen et al. 2018b).

Recently, a number of new techniques have been developed that can make much greater use of sparse biological data (Dunstan et al. 2011, Melbourne-Thomas et al. 2012, Foster et al. 2013, Ovaskainen et al. 2017). New statistical techniques, such as Species Archetype Models (SAMs; Dunstan et al. 2011), can group multiple species with similar responses to environmental predictors together. In SAMs, rarer species are modeled together with more prevalent species that show similar distributional patterns, enabling study of the distributional patterns of a much bigger proportion of the fauna than previously. Mapping these species groupings also reveals insights into spatial differences in community structure, an important factor for the functioning of an ecosystem. Another important recent development allows for quantifying outcome uncertainty from press perturbations of qualitative network topologies (Dambacher et al. 2002, Raymond et al. 2011, Melbourne-Thomas et al. 2012). Qualitative network topologies provide useful insights into ecosystems where data are too limited to fully parameterize a quantitative ecosystem model (Dambacher et al. 2009). To reveal insight into how different nodes of the network respond to the simulated perturbation, qualitative network models (QNMs) incorporate feedbacks and indirect effects in the network topology into predictions of system responses to press perturbations (MelbourneThomas et al. 2012). This enables a powerful test of the effects of putative ecosystem drivers on ecosystem functioning for little-known systems.

In our study, we use a space-for-time modeling approach for assessing the spatial distribution and structural dynamics of the Antarctic benthic ecosystem (Fig. 1). First, we use statistical models to identify groups of species that respond to the environment in the same way (Species Archetype Models) and use predictions of these groups to map the distributions of demersal fish from trawl data on the East Antarctic continental shelf and upper slope (Causse et al. 2011). To identify whether there are consistent patterns across phyla, we compare the distributional patterns to mapped predictions of benthic macroinvertebrates from a previous study in the same region (Jansen et al. $2018 b$ ), and use these to quantitatively identify four distinct habitats characterized by depth and slope that are shared across multiple phyla. We conceptualize the network topology of the broad Antarctic benthic ecosystem, test how changes in depth and slope affect ecological structure and validate results from a QNM with observed species abundances from the study region. Further, we use the validated models to project community responses to increases in primary production, which is a likely future scenario (Laufkötter et al. 2015). The analysis gives insight into the functioning of a biodiverse ecosystem in a remote environment and shows how predicted dynamics in community structure can be validated and located spatially using species distributions.

\section{Methods}

Study area

The study region is the George $\mathrm{V}$ continental shelf and slope in East Antarctica, spanning latitudes $139^{\circ} \mathrm{E}$ 


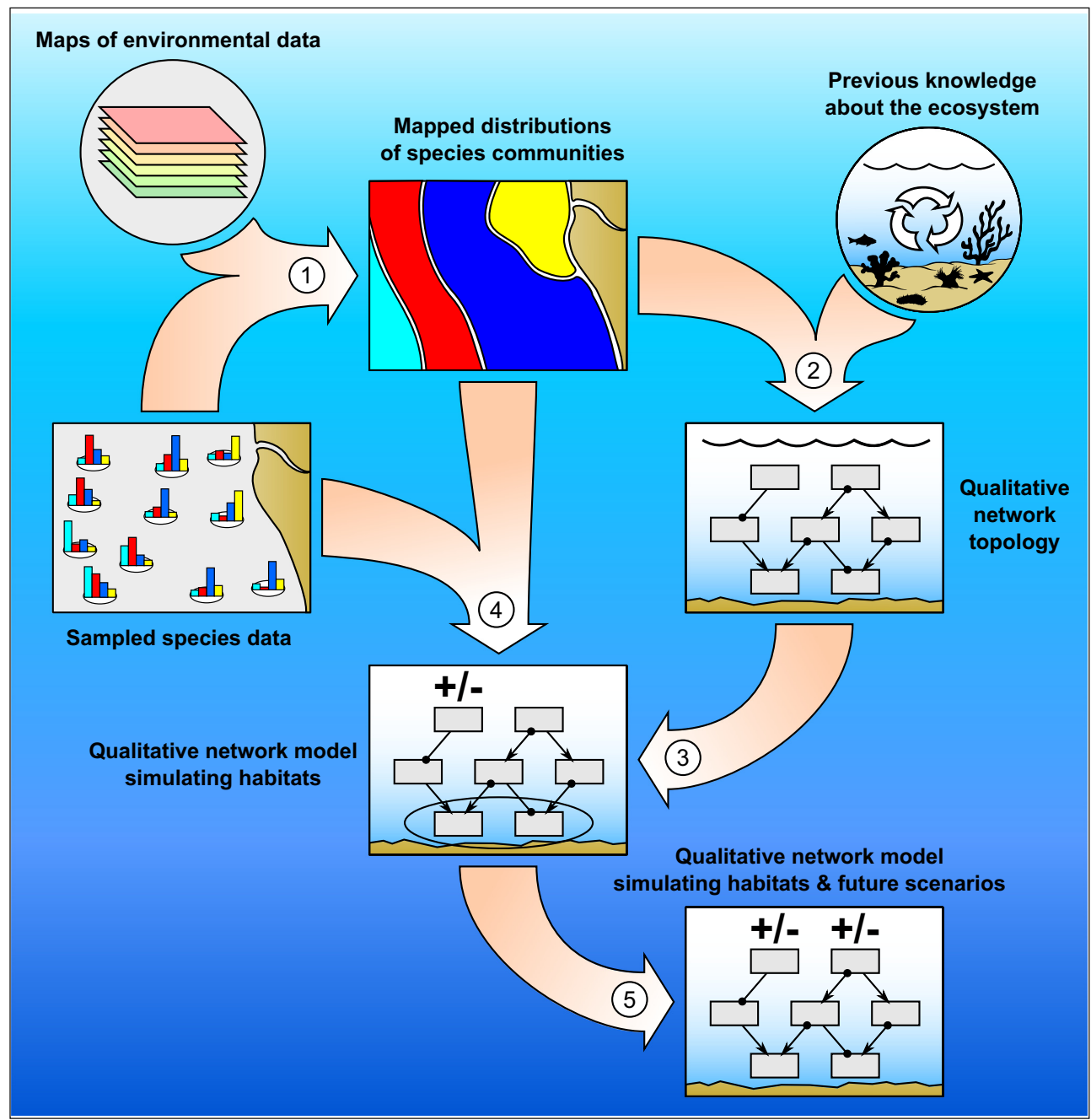

FIG. 1. Overview of our approach combining spatial and qualitative models to learn about species community structure in different habitats and predict effects of a changing environment. (1) Mapped distributions of distinct communities are based on statistical relationships between "species" (or operational taxonomic unit) distributions and environmental variables. In our study, we use species archetype models to map communities. (2) The qualitative network topology describes interactions between the species community and its physical and biological drivers. (3) Using press perturbations of important physical drivers, the qualitative network model simulates the composition of species communities in different habitats. (4) Comparing predictions from the qualitative and spatial models and the sampled species data allows validating the network topology to ensure all key drivers are captured in the model, and that model responses to drivers are consistent with observations. Importantly, the combination of the two different models allows spatial definition of the boundaries of simulated habitats from the qualitative network model, and identification of species associated with each habitat. (5) Future scenarios, such as increased primary production near the Antarctic continent, can be simulated by press-perturbing biological drivers. Critically, these simulations give new insight into how the composition of species communities can respond to environmental changes.

to $147^{\circ} \mathrm{E}$ from the Antarctic coastline to the shelf-break at around $65.5^{\circ} \mathrm{S}$, and ranging between 200 and $2,000 \mathrm{~m}$ depth. The continental shelf in this region is typically between 500 and $700 \mathrm{~m}$ but punctuated by bathymetric features including the Mertz and Adélie Banks (200-250 m depth) and the George V and Adélie Basins (depths up to $1,300 \mathrm{~m}$; Fig. 2). The oceanography in this area is mainly influenced by the Mertz Glacier Tongue and the adjacent Mertz Polynya (Cougnon et al. 2013), an area of ice-free water that drives water circulation (Massom et al. 2001) and supports a relatively long growing season of phytoplankton (Sambrotto et al. 2003, Beans et al. 2008).

The Antarctic continental shelf contains significant levels of biodiversity (Clarke et al. 2004, Gutt et al. 2004, Brandt et al. 2007) due to a combination of exceptional environmental conditions. While Antarctic water temperatures are relatively stable year-around, light availability, water column stratification, salinity, ocean currents, and primary productivity are highly variable due to high seasonality of sunlight and the resulting melting and freezing processes of sea ice and ice-shelves 


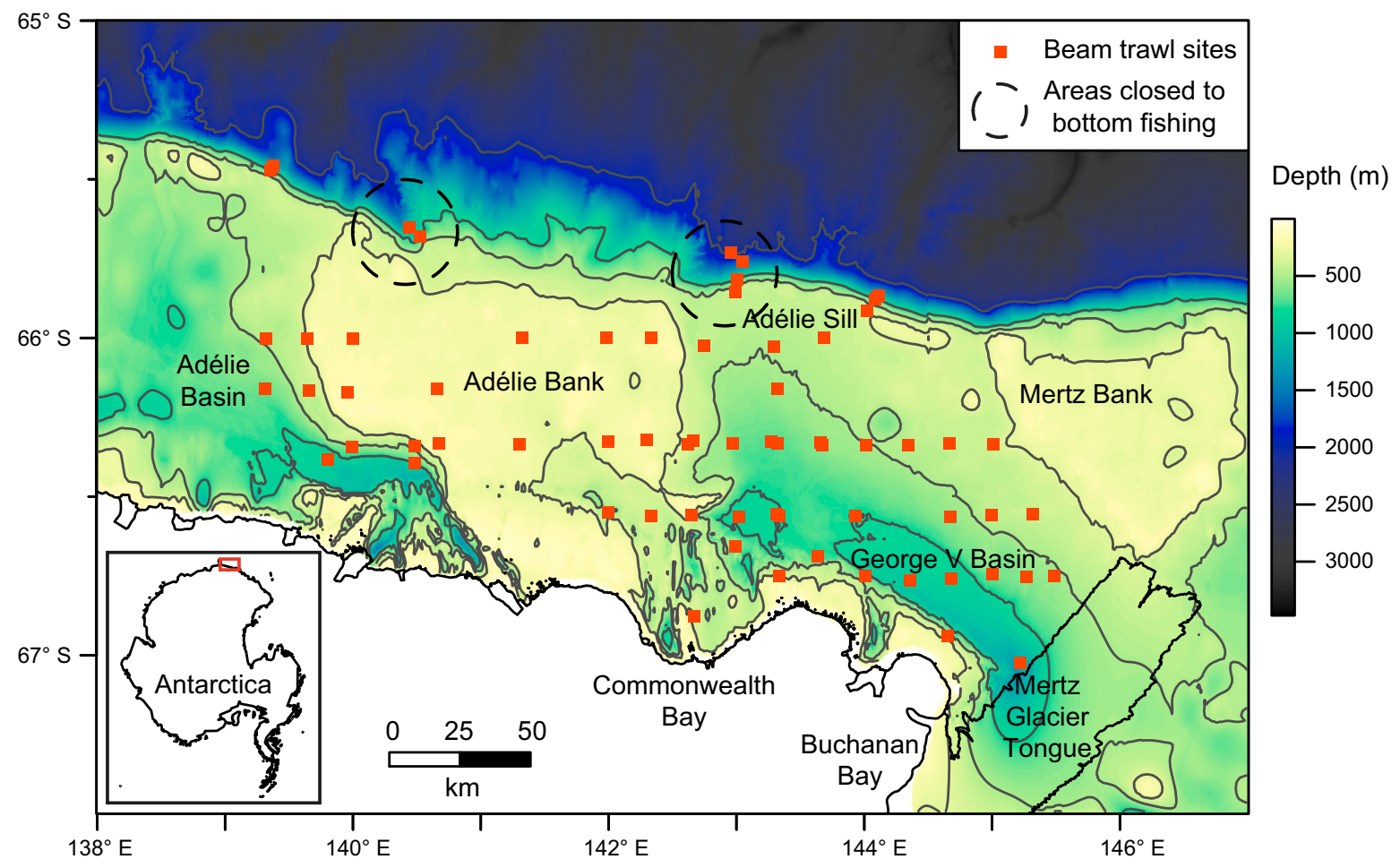

FIG. 2. East Antarctic continental shelf in the George V region with trawl-sample locations. Background colors and contour lines in gray indicate depth (Beaman et al. 2011). All areas shallower than $550 \mathrm{~m}$ are closed to bottom fishing, as are the two deep areas (dotted circles) due to the presence of vulnerable marine ecosystems (Jones 2017). The inset map (bottom left) shows the location of the study area (red box).

(Convey et al. 2014, Post et al. 2014). The periodic calving of massive icebergs influences ocean currents, the activity of polynyas, and icebergs can scour the seafloor and disturb benthic habitat at depths of up to $500 \mathrm{~m}$ (Gutt 2001).

Suspension feeders are a key component of the diverse Antarctic benthic ecosystem (Orejas et al. 2000), providing habitat and food. Fish species such as Trematomus loennbergi and T. lepidorhinus settle on and hide in the complex habitat, while other demersal fish, such as Prionodraco evansii, Dolloidraco longedorsalis, Trematomus scotti, and Chionodraceo myersi, show little to no association with benthic invertebrates (Gutt and Ekau 1996). Although some benthic invertebrates and demersal fish can be, at least at times, closely associated, there has been to our knowledge no published study to date investigating correlations in their spatial distributional patterns in the Antarctic. Demersal fish have been found to primarily inhabit the deeper inner-shelf depressions and their upper sides, and descriptive analyses of the region have found differences in the community structure between the continental slopes, the basins, and on the shelf (Koubbi et al. 2010, Causse et al. 2011). Diverse and abundant benthic macrofaunal communities are found along the shelf-break and on the shallower section of the shelf between 200 and $600 \mathrm{~m}$ (Post et al. 2011). Modeling work indicates widespread suspension feeder cover on the banks (Jansen et al. 2018a), and distinct communities of benthic macroinvertebrates particularly along the steep edges of the banks and the coastal and continental slopes (Jansen et al. 2018b). A more detailed descriptive analyses of the fish community inhabiting the George V shelf can be found in Causse et al. (2011), and a detailed description of the benthic invertebrate communities in Post et al. (2011).

\section{Biological data}

We used previously published data for abundances of demersal fish (Causse et al. 2011) and benthic macroinvertebrates (Robineau et al. 2018) from the George V shelf. All biological data were collected during the Collaborative East Antarctic Marine Census (CEAMARC) for the Census of Antarctic Marine Life from December 2007 to February 2008 (Hosie et al. 2011).

Demersal fish sampling and identification.-Beam trawls ( $3 \mathrm{~m}$ wide, $1.39 \mathrm{~m}$ high, mesh size in the cod end $10 \times 10 \mathrm{~mm}$ ) were used to collect demersal fish at 66 sites. Sample sites were placed along different environmental gradients spanning banks, shelf depressions, coastal and continental slopes (Fig. 2), and spanning the entire shelf from $139^{\circ} \mathrm{E}$ to $145^{\circ} \mathrm{E}$. Trawl distance at the bottom ranged mostly between 500 and $1,000 \mathrm{~m}$ 
(range between 85 and $1,698 \mathrm{~m}$ ) at depths of 150 $2,065 \mathrm{~m}$. There was no spatial-, depth-, or slope-related bias in the duration/distance of the trawls, and we accounted for the distance trawled in the analysis of the fish abundance. Mounted video cameras were used to study avoidance of the trawl by fish.

Fish species were identified following Gon and Heemstra (1990), based on fresh or preserved specimens and, where possible, DNA barcoding. A total of 53 species belonging to eight families were identified (Appendix S1: Table S1), with Nototheniidae the most abundant family $(44.7 \%$ of individuals), followed by Bathydraconidae (19.8\%; Causse et al. 2011). A detailed description of sampling and identification and a thorough descriptive analysis of the demersal fish diversity in the region can be found in Causse et al. (2011).

Benthic invertebrate sampling and identification.-Benthic invertebrate abundances in percent coverage were estimated from underwater still images, collected using a forward-facing 8 megapixel Canon EOS 20D SLR (Canon, Tokyo, Japan) with two speedlight strobes mounted on the beam trawls used to collect demersal fish. Hereafter, "trawls" refers to the fish trawls and "transects" refers to all still image transects. Still-cameras taking pictures every $10 \mathrm{~s}$ were deployed at 32 sites, and transect length was mostly between 4 and $6 \mathrm{~km}$ long, with the exceptions ranging between 3 and $16 \mathrm{~km}$. Tow speed was 2.5 knots $(1 \mathrm{knot}=0.51 \mathrm{~m} / \mathrm{s})$, and the average field of view of the seabed was $3.5 \mathrm{~m}$, ranging between 0.6 and $7 \mathrm{~m}$ at times. A total of 2,724 out of 3,442 images were usable for analysis. The bottom onethird of each image was scored. For each image, the abundance of each species/morphotype was estimated within $5 \%$ bins from $0 \%$ to $50 \%$, and within $10 \%$ bins from $50 \%$ to $100 \%$.

Benthic invertebrates were identified to the highest taxonomic resolution possible. Where species identification was not possible, specimens with similar overall appearance were grouped into morphotypes (operational taxonomic units). A total of 172 benthic invertebrate morphotypes were identified and grouped into three feeding mode classes for analyses. A detailed list of identified benthic invertebrate morphotypes containing information about their taxonomic class, their feeding type, and their association with the different species archetypes has been published in the supplementary material in Jansen et al. (2018b).

Feeding modes of fish and invertebrates. - Feeding mode is a functional trait that can play an important role in determining species distributions (Gaston 1987, Lombarte et al. 2003, Jansen et al. 2018c). In our study, we build a qualitative network topology based on the primary feeding modes of demersal fish and benthic macroinvertebrates and validate the qualitative network analysis using quantitative information about species distributions (see Qualitative network model).
For each species of fish, we identified their primary feeding mode (either zooplankton, zoobenthos, or nekton) using FishBase and published literature (Lombarte et al. 2003, Duhamel et al. 2010; Appendix S1: Table S1; database available online). ${ }^{7}$ We were unable to assign primary feeding modes to only seven species and thus did not use those species to validate the QNM.

Benthic invertebrates from the region have previously been classified into suspension feeders, deposit feeders and predators by Jansen et al. (2018c), using their taxonomy and morphology along with expert knowledge. We used the previously published data set containing the full list of species, their feeding types and abundances (Robineau et al. 2018).

\section{Environmental data}

For mapping the spatial distribution of demersal fish, we used the same environmental covariates considered for mapping the distribution of benthic invertebrates as in Jansen et al. (2018b). Specifically, we considered depth, slope of the seafloor, and topographic position index derived from Beaman et al. (2011), ocean current speed, tidal current speed, and temperature at the seafloor derived from a regional oceanographic model (Cougnon et al. 2013), and three estimates of the availability of food at the seafloor from Jansen et al. (2018c; viz. food particles arriving near the seafloor after sinking from the surface, horizontal flux of food along the seafloor, and food particles settling onto the seafloor). We excluded environmental covariates that were highly correlated with variables already selected, such as surface productivity (highly correlated with the number of sinking particles arriving near the seafloor; Pearson's $r=0.971$ ), and roughness of the seafloor (highly correlated with slope; Pearson's $r=0.992$ ).

Similarly to Jansen et al. (2018b), we corrected exceptionally high values from the map of settling particles to a value of 1,000 (35 out of 2,515 grid-cells contained values between 1,035 and 5,122), as these high values are likely an artefact of the modeling process rather than a real pattern to be observed.

\section{Modeling approaches}

We used a multi-model approach for analyzing the benthic ecosystem on the George V shelf (Fig. 1). We first mapped the spatial distribution of demersal fish in the region using SAMs and set up a network topology using previously published detailed descriptions of the Antarctic ecosystem (see Qualitative network model for details). We then ran a QNM using press perturbations to simulate different habitats and compare responses of the species communities to the predicted species community patterns from the SAMs. Finally, we used the QNM

\footnotetext{
${ }^{7}$ www.fishbase.se
} 
to test how anticipated future increases in primary production will likely affect the species communities.

Species archetype models.-For statistical analysis of the fish data, we used SAMs (Dunstan et al. 2011, 2013), which are based on finite mixtures of generalized linear models (GLMs) where mixing occurs across species. The probability of membership of species to each species archetype group is estimated during model fitting and the response of each archetype group to the covariates is described by a GLM. In this way, multiple species can be modeled by a single GLM that describes the group response to the environment. The SAM models do not consider spatial autocorrelation as this would require a separate model for each species. We initially developed SAMs for both count data (number of individuals per species) and presence-absence data, but a preliminary analysis using the count data did not show reliable results due to the high number of rare species, and the generally low count of fish, which results in data set characteristics more similar to presence-absence data. Therefore, we converted our data set to presenceabsence data for analysis and used a Bernoulli distribution in the SAM analyses.

For the SAM analysis, we considered all the environmental covariates outlined in Environmental data and additionally included the logarithm for slope and a quadratic term for depth to account for exponential and hump-shaped responses in the data. We did not consider interactions terms and all environmental variables were included in the final model as each one was relevant to at least one species archetype (see also Fig. 3). As suggested in Dunstan et al. (2011), we used Bayesian information criteria (BIC) for selecting the optimal number of species archetypes. We ran 50 iterations of the same model with random starts and extracted the BIC in each of these models to ensure that inference was based on the global maximum of the likelihood surface. We then used the model with the optimal number of species archetypes, and the suite of maps of environmental covariates to predict the probability of occurrence of each species archetype across the study area. We restricted the prediction area to the continental shelf down to $\sim 2,200 \mathrm{~m}$, the maximum depth that the beam trawl was deployed, and do not predict below the Mertz Glacier Tongue where we have no samples and where environmental conditions might differ to the study region.

Deriving a constant offset for a logit link function and a Bernoulli response is not possible, and therefore trawl distance was not included as an offset in the SAMs. While univariate models may underpredict rare species, SAMs are typically better at predicting rare species (Hui et al. 2013), giving confidence in the model outputs.

For the statistical analysis, we used $\mathrm{R}$ version 3.3.1 (R Core Team 2016) and SAMs were developed using the R package SpeciesMix (Dunstan et al. 2011).

Qualitative network model.-1. Model setup.-For describing and analyzing biological and environmental interactions in the Antarctic benthic ecosystem described by each SAM group, we used a QNM based on a qualitative network topology with signed digraphs (Fig. 4). Species archetype membership was composed of all species with a probability of 0.8 or greater for that group. We used previous detailed descriptions of this

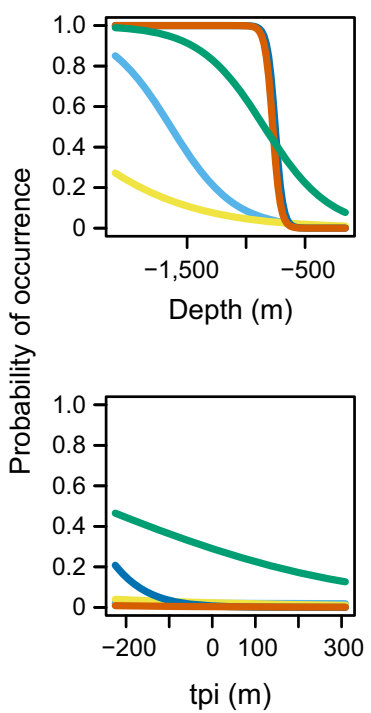

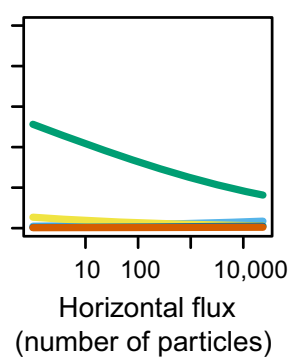
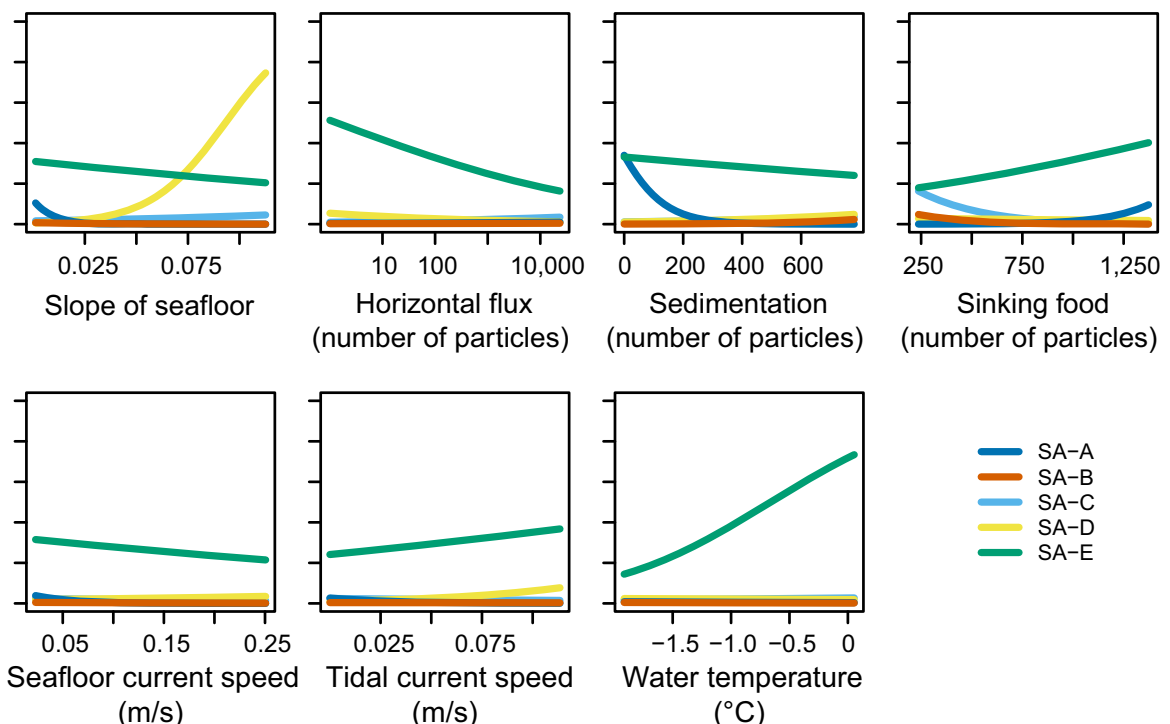

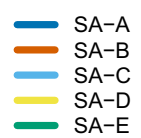

$-1.5-1.0-0.50$

Water temperature

$\left({ }^{\circ} \mathrm{C}\right)$

FIG. 3. Probability of occurrence for five species archetypes (SA) of demersal fish in relation to each of the environmental variables used in the analysis. Species archetypes change strongly along an environmental gradient if the line is steep, indicating which environmental predictor variables are important in determining high or low probability of occurrence for each species archetypes. The abbreviation tpi stands for topographic position index. 


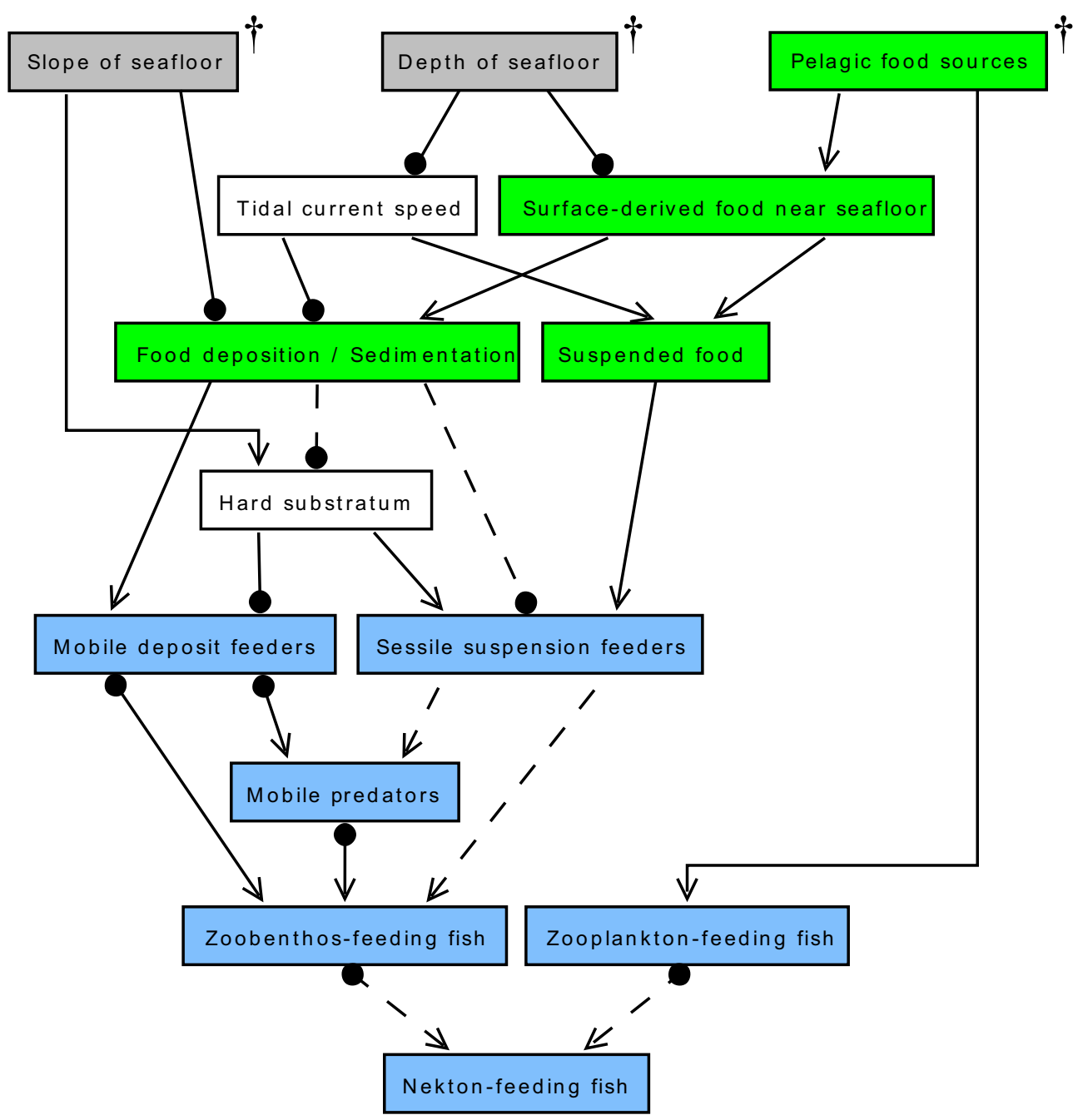

FIG. 4. Qualitative network topology describing interactions and responses in the Antarctic benthic ecosystem. The color code distinguishes between different categories of physical drivers (gray, white), ecological drivers (green), and key functional groups (blue). "Pelagic food sources" included surface primary production, secondary production through zooplankton, and the export of this production toward the seafloor. An arrow head shows positive influence; a circle head shows negative influence; dotted lines indicate weak or uncertain interactions. The model also includes self-limitation for each component of the network (not shown on diagram). Drivers that we press-perturbed in the qualitative network analysis are marked $(\dagger)$.

region and of the Antarctic benthic marine ecosystem (Beaman and Harris 2005, Gutt 2007, Koubbi et al. 2010, Post et al. 2010, 2011, 2017, Causse et al. 2011, Gutt et al. 2011, Gillies et al. 2013, Jansen et al. 2018c) to choose which components to represent in the network model and the nature of their relationships, including whether the relationship is uncertain or weak (represented by dotted lines in Fig. 4). A detailed description of each interaction in the network can be found in Appendix S1: Table S2. For our analysis, we focused on physical and biological interactions that are affected by changes in either depth, slope, or food availability, which the SAM models indicated were the structuring physical forcing that determined species composition. Based on the models for both demersal fish and benthic species we expect that the species present in each combination of these physical forcing will differ. In our network topology, we use the simplified term "pelagic food sources" to represent the complex pelagic ecosystem dynamics between primary production, zooplankton communities, and the export of particulate organic carbon. While the strength of individual nodes in the pelagic ecosystem differs, general increases in surface primary production positively influence both the zooplankton abundance and the export of particulate organic carbon. This simplified representation reduces model complexity while still allowing us to assess how overall changes in primary production affect the benthic ecosystem. We have chosen not to include icebergs in our network topology, which can play an important role in the ecosystem (Gutt et al. 
2007) but are difficult to predict because of their stochastic occurrence. We also did not include non-tidal ocean currents because in contrast to tidal currents, they are affected by depth and slope in a less consistent manner. In our analysis, we use only the network topology presented in Fig. 4 and have not compared results across alternative model structures.

The nodes and interactions of the network model were then analysed using QPress (Melbourne-Thomas et al. 2012). QPress uses a simulation approach for evaluating the uncertainty of the effects of press perturbations in a network. We ran 10,000 simulations of the network, where in each simulation a random value between 0 and 1 ( 0 and 0.5 for uncertain or weak interactions) is drawn from a uniform distribution and allocated to each interaction (positive or negative) in the network. Thus, we used 10,000 quantitative networks that were qualitatively identical to the signs of the original qualitative network.

For simulating the four main benthic habitats determined from the SAMs (i.e., deep-flat, deep-steep, shallow-flat, shallow-steep), we simultaneously changed slope and depth by individually assigning either a positive or a negative sign (Appendix S1: Table S3). Further, to simulate anticipated future conditions of increased primary production (Jones et al. 2014), we increased pelagic food sources in each of those four habitat simulations, resulting in a total of eight scenarios. We use the number of positive outcomes for each trophic group in the eight scenarios when comparing QNM predictions.

2. Model evaluation.-Combining SAM models, abundance data and QNM models allows us to have information on the species composition at any location and to describe in broad terms how we expect the ecosystem in that location to function. In our study, the environmental responses and spatial distribution of the SAMs (Figs. 3, 5) indicate four different ecosystem types and allow us to identify the location where they will occur. To determine if the trophic groups modeled in the QNM are responding in the way that the QNM predicts, we evaluate the QNM results for different combinations of depth and slope using the abundances of demersal fish from the benthic trawls (Causse et al. 2011), and the estimated cover of benthic invertebrates from seafloor images (Robineau et al. 2018).

The SAMs for both fish and invertebrates result in a total of 11 species archetypes from the two studies. As suggested from the species archetype responses to the environment (Fig. 3) and the visual comparison of the spatial maps (Fig. 5), we classified the region into four main habitats using $k$-means clustering of the species archetype distributions (target of four clusters using 1,000 random starts; Appendix S1: Fig. S5). Within each habitat, we then calculated mean proportional abundances of all faunal categories as observed in the samples (Appendix S1: Table S4). We chose to use proportional abundances between broad feeding types rather than absolute abundances to allow comparison to the QNM results, which also show proportional changes in abundance.

For illustrating the spatial match between species archetype distributions based on presence/absences and the observed species abundances from the sample sites, we aggregated the abundances of all fish/invertebrates that occur in both the same species archetype and have the same feeding mode for each site (Appendix S1: Figs. S1, S2).

We adjusted fish counts for sampling effort by dividing through the distance trawled at each site. Estimates of the percentage cover of invertebrates did not need adjusting because they are mean values across transects.

\section{RESUlts}

\section{Species archetype models of demersal fish}

Based on SAMs, we find five distinct species archetypes of demersal fish on the George V shelf, each containing between 5 and 16 species from a total of eight families (Fig. 5; a hard-classed prediction of the fish species archetypes summarizing their spatial distribution is given in Appendix S1: Fig. S4). Demersal fish can be found along three main habitat types, namely shallow banks ( 200-300 m), shelf depressions, and the continental slope (Fig. 5). The confidence in the predictions is high (Fig. 5; Appendix S1: Fig. S3).

Species archetype A (SA-A) is made up of species belonging to the taxonomic families of Artedidraconidae, Bathydraconidae, and Zoarcidae, and is predicted for deep $(\sim 400-1,200 \mathrm{~m})$, flat habitat that has a lot of food arriving near the seafloor alongside a low topographic position index (i.e., which is typical for the inner-shelf depressions). Unexpectedly, the analysis suggests this species archetype is more likely to occur at low levels of sedimentation (Fig. 3), which is atypical for the basins. The number of particles arriving near the seafloor and the number of particles settling on the seafloor are positively correlated in this area, which potentially downplays the importance of settling particles in the model. Similar to SA-A, SA-B also occurs in the inner shelf depressions but contains a wider range of taxonomic families with less common and less abundant species and the model doesn't predict the occurrence of this archetype very well (Fig. 5; Appendix S1: Fig. S3).

Species archetype $\mathrm{C}$ is dominant along the shelf break and continental slope, preferring deep and steep habitat. It is comprised of equal amounts of zoobenthos- and zooplankton-feeding species, is dominated by species from Channichthyidae, Liparidae, and Zoarcidae, and contains the only Macrouridae and Muraenolepididae found in the samples. Although this species archetype is predicted mainly along the deep and steep shelf-break, zooplankton-feeding species also sometimes occur on the shelf (Appendix S1: Fig. S1). 

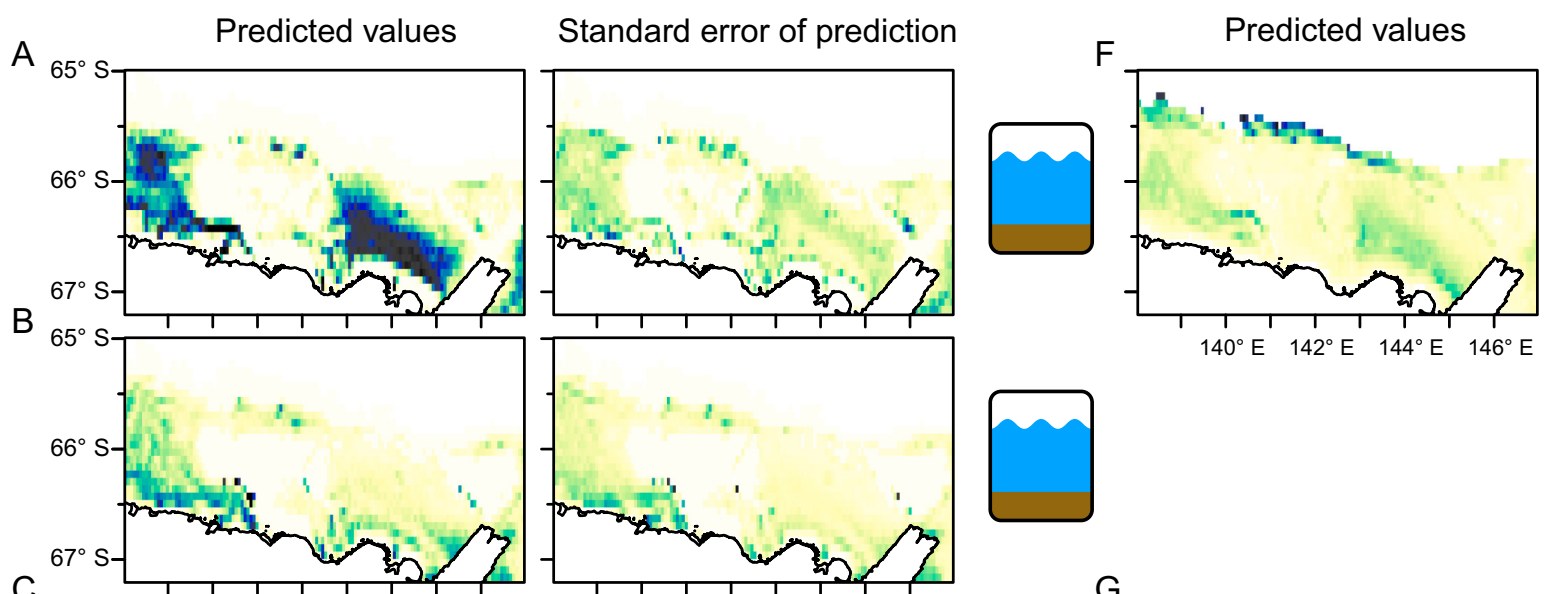

C
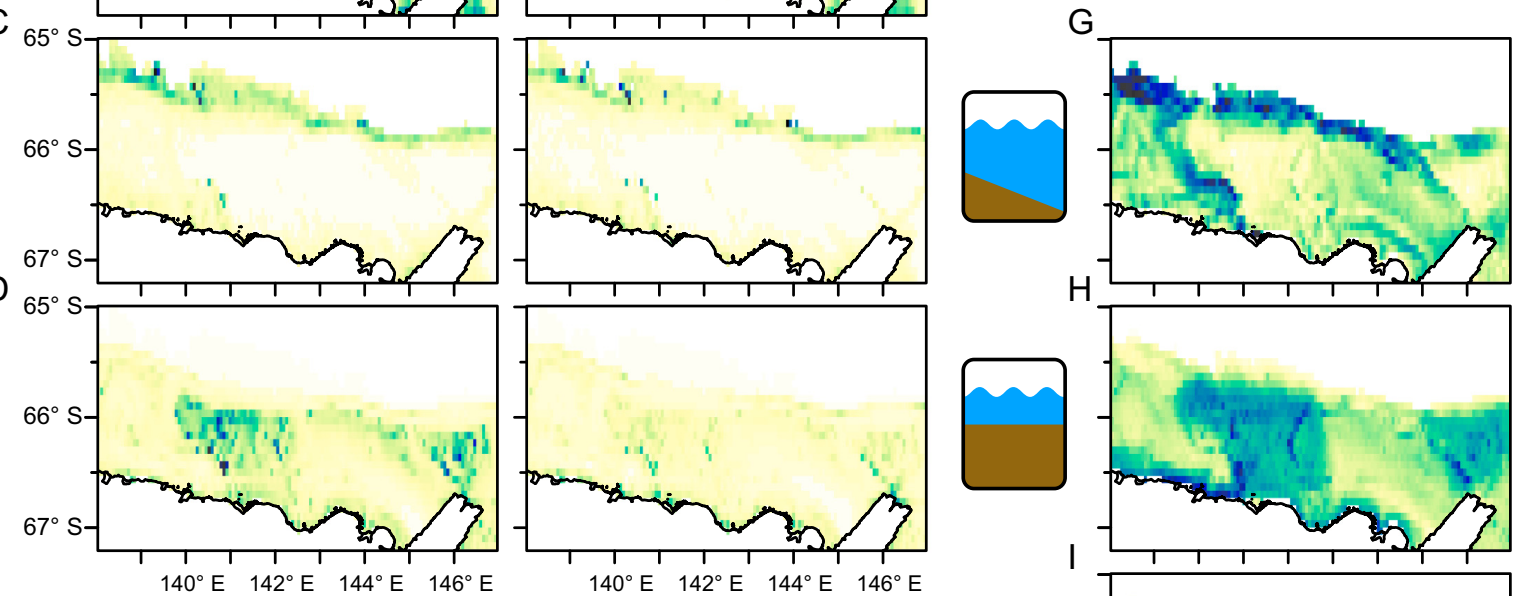

$\mathrm{E}$
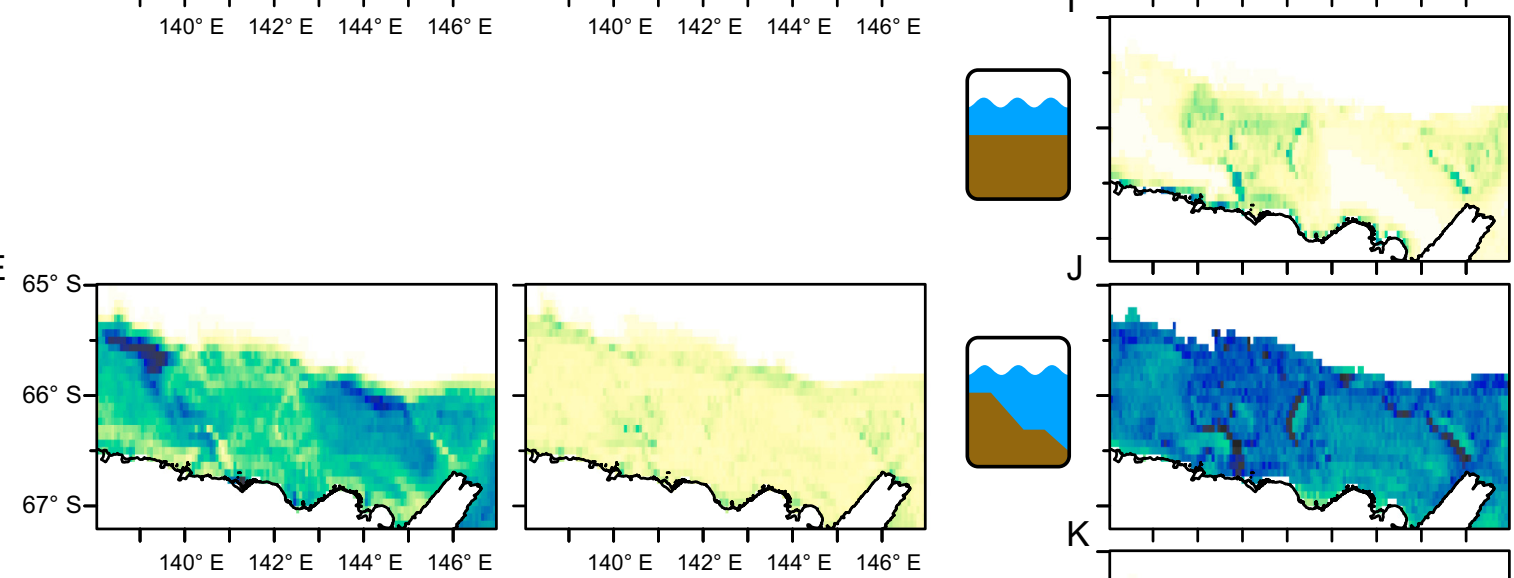

Probability of occurrence

Probability of occurrence
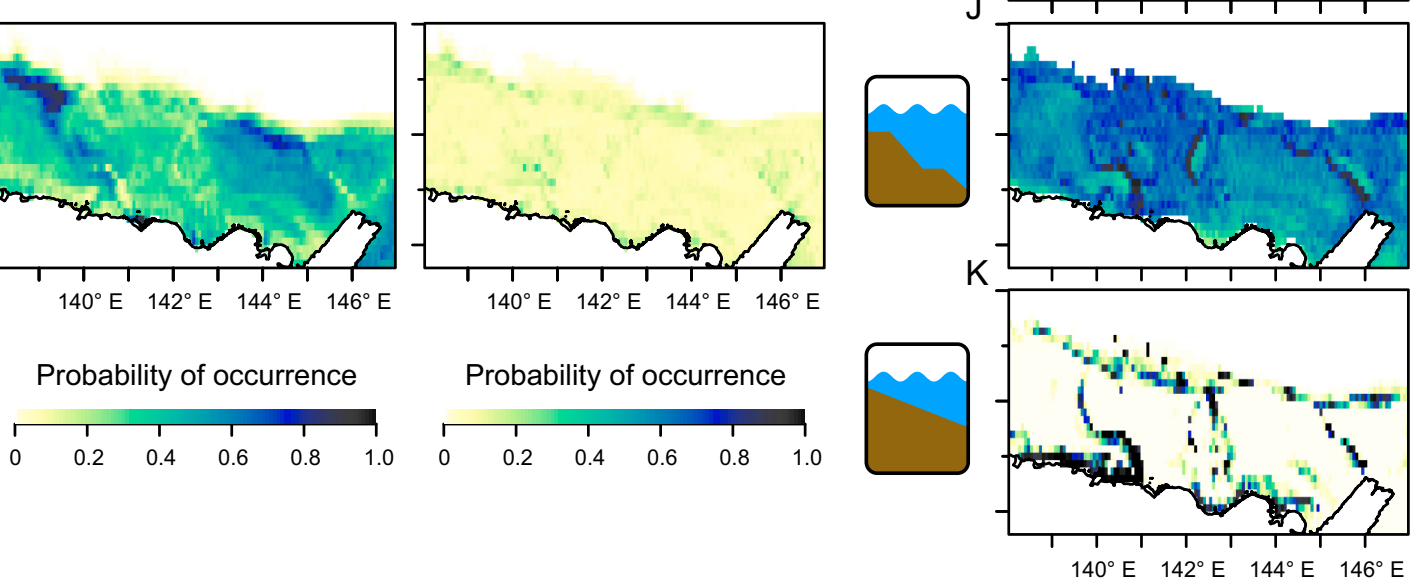

FIG. 5. Comparison of species archetype model results for demersal fish species (A-E, this study) and for benthic invertebrates (F-K, from Jansen et al. 2018b). The area under the Mertz Glacier Tongue is excluded from the predictions. Drawings in the column between fish and invertebrates indicate the main habitat corresponding to each pair of species archetypes. From top to bottom, these are: Deep-flat (A, B, F), deep-steep (C, G), shallow-flat (D, H, I), widely distributed (E, J), shallow-steep (K). Species archetype models are based on observations from 68 sites (fish) and 41 sites (invertebrates). 
Species archetype D (SA-D) contains a mix of feeding types from a wide range of species and is predicted mainly on the shallower banks, where it occurs in low numbers. Certainty in the prediction is high, but the environmental preferences of SA-D are complex. Although the mapped predictions show higher probabilities on the shallower banks, the probability of occurrence for this archetype is higher for deeper and steeper habitat with a low topographic position index (Fig. 3).

Species archetype E contains common, abundant, and widely distributed species, mainly from the families Channichthyidae and Nototheniidae. The model shows a positive correlation between predicted and observed values, yet the relationship is relatively weak $\left(R^{2}=0.364\right)$, and the model underestimated values where observed abundances are high (Appendix S1: Fig. S3).

The predicted spatial distribution of demersal fish shows similarities to the distribution of benthic macroinvertebrates in this region (Jansen et al. 2018b; highlighted in Fig. 5F-K and in Appendix S1: Table S5), although in contrast to the benthic macroinvertebrate archetypes, the demersal fish archetypes generally do not change strongly along environmental gradients (Fig. 3). The $k$-means clustering of the species archetype distributions into four main habitats broadly classifies the region along gradients of depth and slope (Appendix S1: Fig. S5), although the very small number of samples (two and four samples for invertebrates and fish, respectively) within the shallowest and steepest category prevents comparing this habitat to all other habitats. Within the remaining three habitats, suspension feeders and zoobenthos feeding fish dominate the invertebrate and fish communities, particularly in the shallow-flat habitat $70.4 \%$ for suspension feeders and $69.3 \%$ for zoobenthos-feeding fish; Appendix S1: Fig. S6, Table S4). Deposit-feeding invertebrates occur proportionally more often in deep habitats while numbers of predatory invertebrates are between $13.5 \%$ and $16.4 \%$ across all evaluated habitats. Relative proportions of zooplankton-feeding fish and nekton-feeding fish are close to two times higher in the deep than in the shallows $39.1 \%$ and $38.5 \%$ in the deep vs. $23.3 \%$ in the shallowflat for zooplankton-feeding fish; $7.8 \%$ and $9.4 \%$ in the deep vs. $4 \%$ in the shallow-flat for nekton-feeding fish).

\section{Qualitative network model}

The results from simulating different benthic habitats using press perturbations on depth and slope as key "drivers" show varying amounts of agreement with the validation data dependent on the functional group (Fig. 6). Proportional changes in abundances of suspension-feeding invertebrates and zoobenthos-feeding fish, the functional groups with the largest proportional abundances within the benthic invertebrates and demersal fish, are predicted correctly from the QNM across all three habitats that were compared. In

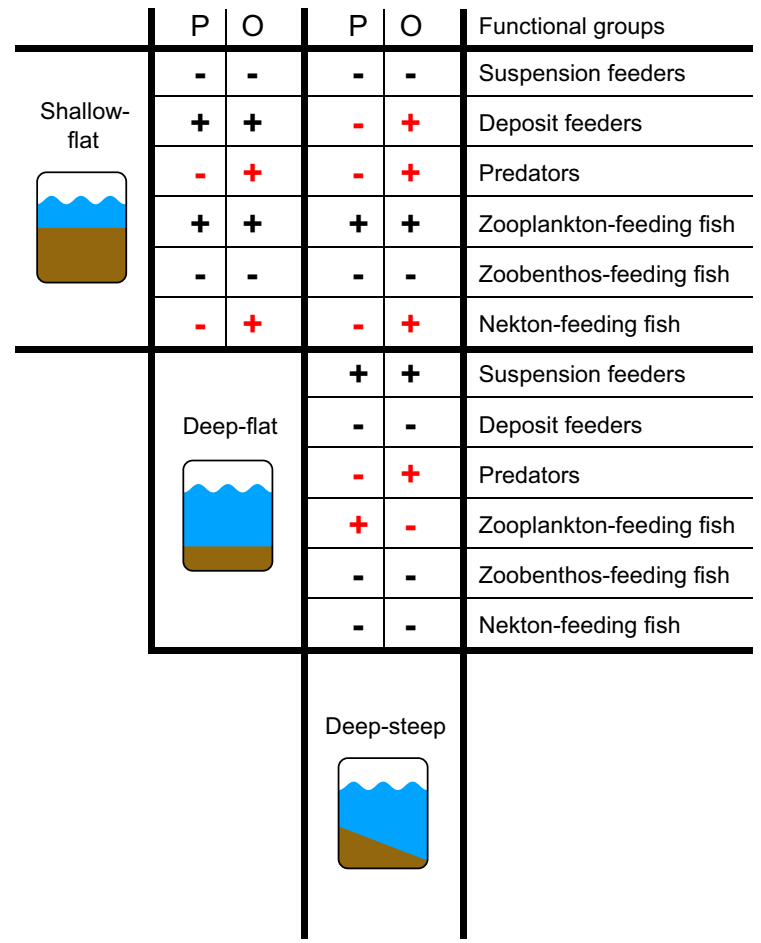

FIG. 6. Cross-comparison of changes in macroinvertebrate and fish functional groups between Antarctic benthic habitats. Predicted change $(\mathrm{P})$ for each functional group is the trend change in total positive outcomes after 10,000 press perturbations of the qualitative network model. Observed change $(\mathrm{O})$ is the change in functional group abundance approximated through the species archetype models (see Methods for details on the calculation). Table is read from top-left to bottom-right, e.g., moving from a shallow-flat to a deep-flat habitat, the qualitative network model predicts a decrease in suspension feeders $(-)$, which is confirmed by the observed values $(-)$. Red symbols are instances in which observed values do not confirm the predicted changes (see Appendix S1: Fig. S5 for absolute values)

contrast, five out of six predictions for changes in abundances of predatory functional groups are not supported by the validation data. The other discrepancies in our results are that deposit feeders are predicted to decrease from shallow-flat to deep-steep habitats, while the validation data shows the opposite, and that zooplankton-feeding fish are predicted to increase from deep-flat to deep-steep habitat while the observed data show a decrease.

The comparison of habitats shows that, when moving from a shallow to a deeper habitat, relative abundances of zooplankton-feeding fish increase (by $+8 \%$ and $+12 \%$, Fig. 7), while zoobenthos feeding fish $(-18 \%$ and $-47 \%)$ and suspension feeders decrease ( $-48 \%$ and $-9 \%$, Fig. 7). When moving from a deepflat to a deep-steep habitat, abundances of suspension feeders increase $(+39 \%)$, while deposit feeders, zoobenthos-feeding fish, and nekton-feeding fish decrease $(-51 \%,-29 \%,-9 \%)$. 
Increasing primary production and thus zooplankton abundance and particulate organic carbon export, an expected future scenario on the Antarctic continental shelf, results in increased abundances of most seafloor fauna across the simulated habitats (Fig. 7). Hard substrata decrease in all habitats due to the increased sedimentation, and only shallow-steep suspension feeders decrease slightly. The model indicates surface-derived food near the seafloor already at saturating levels in shallow habitat prior to increasing primary production, and therefore increases in surface-derived food only increase the sedimentation load with negative influence on abundances of suspension feeders.

\section{Discussion}

Characterizing the spatial and structural dynamics of ecological communities and validating these patterns with data from the field is key for an ecosystem-based approach to management. Validation of our QNM using SAMs combines two very different approaches, and draws on the strengths of both. The QNMs allow both describing the ecosystem and network topology qualitatively and simulating system-level effects of future change, and the SAMs allow describing distinct species groupings and locating where they occur. This is particularly relevant for areas with limited data, such as the Antarctic or parts of Africa and Asia, where ecosystem characterization will be crucial for developing an ecosystem-based management of marine resources (FAO 2016).

The simple QNM we present here explains the majority of relative changes in abundances of the largest functional groups in transitioning between three of the four main seafloor habitats. The QNM seems to not be able to predict changes in predatory functional groups in transitioning between habitats, presumably because, in reality, predatory fish and invertebrates are responding to more complex biological interactions than those described in the simple network structure used in this study. While our study focusses on East Antarctica, the general characterization into bathymetric classes should hold true not only around the Antarctic continent, but also on other continental shelves and slopes around the world (Danovaro et al. 2010, O'Hara et al. 2011, Woolley et al. 2016). The main difference from the Antarctic to lower latitudes will be related to temperature and seasonality, both of which influence the magnitude of interactions among functional groups in pelagic and benthic systems. For example, particles from phytoplankton blooms at higher latitudes are usually exported to the deeper ocean in higher proportions than at lower latitudes where particles decompose faster during sinking due to higher temperatures and different pelagic food-web dynamics (Lutz et al. 2007, Siegel et al. 2014). However, these differences should not fundamentally change the structure of the system, i.e., deep-flat habitats should still receive more sedimentation than shallow- steep habitats, with concomitant effects on the distribution of fauna. Thus, similar network topologies to those used here can possibly be applied to other regions with limited data.

Although often described as pristine, Antarctic waters have already experienced measurable change (Walther et al. 2002, Constable et al. 2014, Gutt et al. 2015), and will undergo further change in the future due to climate change (Jones et al. 2014, Griffiths et al. 2017). The predicted decrease in sea-ice cover and an increase in melting will likely lead to higher primary production in certain areas, fueling growth of fauna on the seabed (Barnes 2017) and increasing sedimentation. Our results suggest that increases in pelagic food sources are unlikely to lead to major structural changes in benthic communities, as almost all elements in the QNM increased in similar proportions. However, other factors that will change in the future, such as temperature and ocean acidification, are not captured in our network model, but are likely to affect the distributions of species and functional groups differentially (Constable et al. 2014, Griffiths et al. 2017, Marzloff et al. 2018). For example, increases in temperature to above $0^{\circ} \mathrm{C}$ could lead to shifts from species communities tolerant to freezing temperatures to more generalist types of species communities (Griffiths et al. 2017). Because SAMs aggregate the distributions of single species, they can be used to validate additional functional aspects of community structure that form part of a network model, depending on how much is known about the individual species. Incorporating these factors in a more comprehensive QNM can help to better understand whether and how different parts of the ecosystem are likely to change in the future. Further, a network model that incorporates different habitats, or includes estimates for how the ecosystem changes in the transition between habitats, can be used to test how changes in climate or other human pressures such as fishing affect those habitats, facilitating better management of ecosystem pressures.

Our combined assessment shows bathymetry and slope characterize the Antarctic benthic ecosystem into four main habitats, namely the various permutations of shallow/deep and flat/steep. In general, the large bathymetric features corresponding to these habitats are the shallow banks, the steep slopes along the banks and near the coast, the deep inner-shelf depression and the deep and steep continental shelf-break with the upper slope (Fig. 2). On top of this main bathymetric characterization, pelagic food sources and other factors such as ocean currents or disturbance through icebergs (not considered here) affect the system. Indeed, in our case, the location of the highly productive Mertz polynya over the deep-flat section of the shelf can explain some of the differences between predictions and observations, such as why we observe more zooplankton-feeders than predicted on the deep-flat than on the deep-steep section of the shelf. In contrast, the abundance of suspension feeders in the shallow-flat habitat might be generally under- 
Shallow - flat

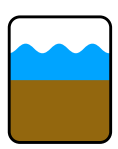

Depth of seafloor

Slope of seafloor

Pelagic food sources

Tidal-current speed

Surface-derived food near seafloor

Hard substrate

Suspended food

Sessile suspension feeders

Food-deposition / Sedimentation

Mobile deposit feeders

Mobile predators

Zooplankton-feeding fish

Invertebrate-feeding fish

Nekton-feeding fish

Deep - flat

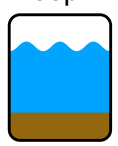

Depth of seafloor

Slope of seafloor

Pelagic food sources

Tidal-current speed

Surface-derived food near seafloor

Hard substrate

Suspended food

Sessile suspension feeders

Food-deposition / Sedimentation

Mobile deposit feeders

Mobile predators

Zooplankton-feeding fish

Invertebrate-feeding fish

Nekton-feeding fish

Deep - steep

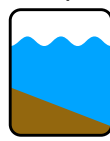

Depth of seafloor

Slope of seafloor

Pelagic food sources

Tidal-current speed

Surface-derived food near seafloor

Hard substrate

Suspended food

Sessile suspension feeders

Food-deposition / Sedimentation

Mobile deposit feeders

Mobile predators

Zooplankton-feeding fish

Invertebrate-feeding fish

Nekton-feeding fish

Shallow - steep

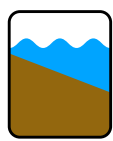

Depth of seafloor

Slope of seafloor

Pelagic food sources

Tidal-current speed

Surface-derived food near seafloor Hard substrate

Suspended food

Sessile suspension feeders

Food-deposition / Sedimentation

Mobile deposit feeders

Mobile predators

Zooplankton-feeding fish

Invertebrate-feeding fish

Nekton-feeding fish

\section{Responses to press-perturbations} on depth \& slope
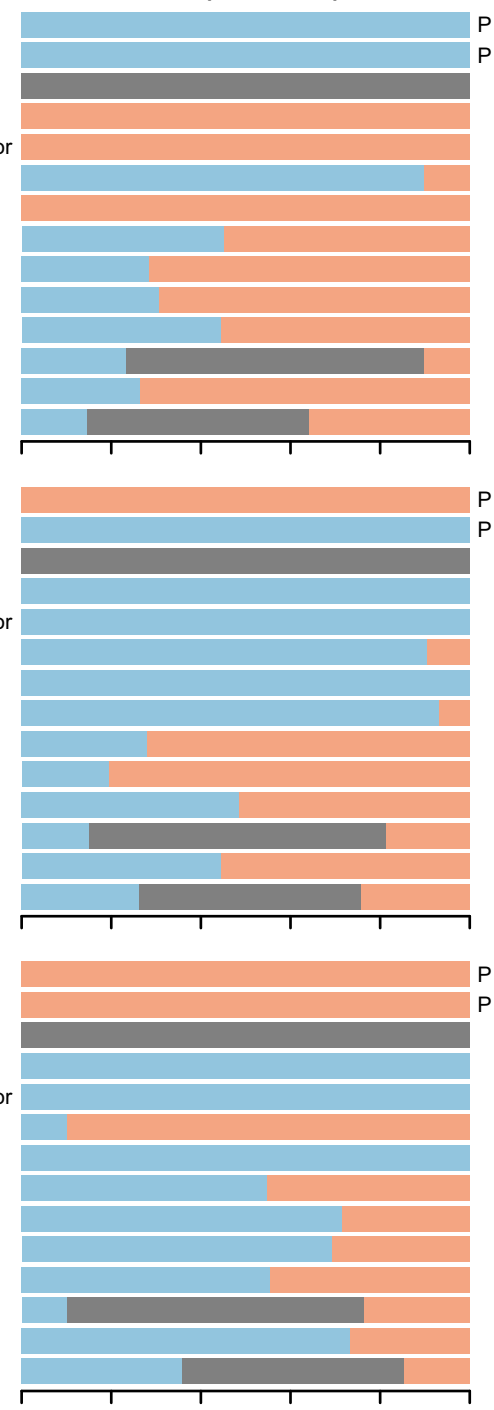

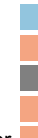

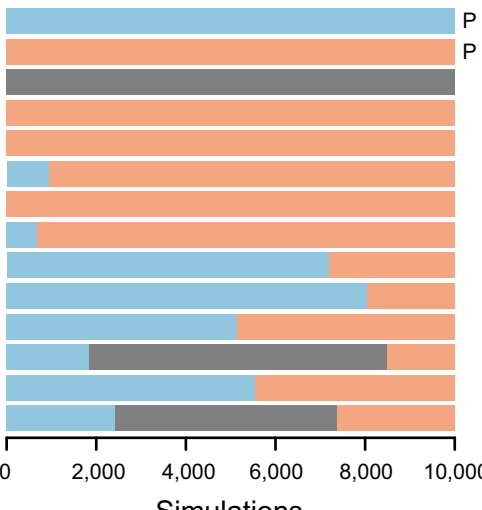

Simulations

\section{Change of responses when} pelagic food sources increase
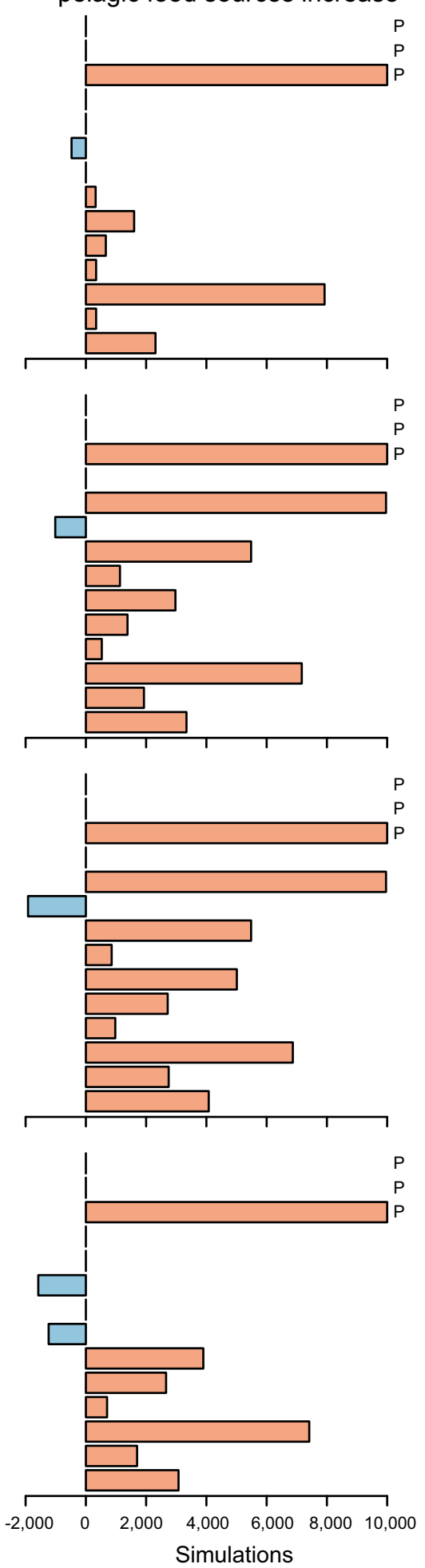

FIG. 7. Evaluation of Antarctic benthic and demersal community responses to press perturbations of the qualitative network model (10,000 simulations). To simulate the four main habitats, we used four combinations of negative/positive effects on depth and slope (Appendix S1: Table S3). Red indicates how often the component increases and blue how often it decreases as a response to the perturbation. Gray indicates how often responses are neutral because of weak or nonexisting links through the network. Variables that 


\section{Fig. 7. (Continued)}

are press-perturbed in the analysis are marked with P. The left column (labeled "Responses to press perturbations on key habitat variables") shows how different components of the ecosystem respond to a change in the habitat (e.g., moving into a shallower and flatter habitat, the amount of surface-derived food near the seafloor increases). The right column shows the difference between the basic model with change in only depth and slope, and when pelagic food sources increase in addition to a change in depth and slope.

predicted because the bathymetry data does not capture small-scale steep features on the largely flat banks. Our results are consistent with previous evidence that bathymetry and its derivatives influence the spatial distribution of species and communities in the Antarctic benthic and demersal ecosystem (Barry et al. 2003, Beaman and Harris 2005, Post et al. 2010, 2017, Douglass et al. 2014, Jansen et al. 2018c). However, we show how bathymetry changes the dynamics of physical and biological processes that influence species communities, providing a better understanding of how different habitats might respond to future changes.

In conclusion, we have shown how our integrated approach can be used to analyze the spatial distribution and the structural dynamics of benthic communities in a diverse but data-limited region. Our integrated approach suggests that no major changes will occur in benthic community structure as result of increased primary production in the future, an insight we could not have gained from using just a single model. The four main habitats identified, described and simulated are commonly found in marine ecosystems globally, and the SAMs can be used to assess confidence in the topology of the qualitative network while also allowing insight into where specific habitats and functional groups can be found across the study area. We suggest that incorporating directly into QNMs how depth and slope influence ecosystem relevant mechanisms will allow to better investigate how species community dynamics change in space and through time, with particular relevance for data-limited regions such as the Antarctic.

\section{AcKNowledgments}

We thank Guy Duhamel for helping to identify feeding strategies of demersal fish and two anonymous reviewers for their comments. Biological samples were collected during the CEAMARC program as part of the IPY \#53 Census of Antarctic Marine Life program. Coastline and glacial features for the figures are taken from the Antarctic Digital Database version 5. J. Jansen is supported by a Tasmanian Graduate Research Scholarship and a QAS Top-Up Scholarship, and has received funding from the Institute of Marine and Antarctic Studies, University of Tasmania, to undertake essential research for this study at the Muséum National d'Histoire Naturelle in Paris, France. This work was completed as part of Australian Antarctic Science project 4124, the French Zone Atelier Antarctique of CNRS and the French ICOTA project 281 from IPEV. Jan Jansen, Nicole Hill, Piers Dunstan, and Craig Johnson conceived and designed the study. All authors contributed to the analysis of the data. Jan Jansen designed all figures and tables and wrote the paper with contributions from all authors. The authors declare that the research was conducted in the absence of any commercial or financial relationships that could be construed as a potential conflict of interest.

\section{Literature Cited}

Anthony, K. R. N., J. M. Dambacher, T. Walshe, and R. Beeden. 2013. A framework for understanding cumulative impacts, supporting environmental decisions and informing resilience based management of the Great Barrier Reef World Heritage Area. Australian Institute of Marine Science, Townsville; CSIRO, Hobart; NERP Decisions Hub, University of Melbourne and Great Barrier Reef Marine Park Authority, Townsville, Australia.

Barnes, D. K. A. 2017. Polar zoobenthos blue carbon storage increases with sea ice losses, because across-shelf growth gains from longer algal blooms outweigh ice scour mortality in the shallows. Global Change Biology 23:50835091.

Barrett, N. S., J. Sanderson, M. Lawler, V. Halley, and A. Jordan. 2001. Mapping of inshore marine habitats in southeastern Tasmania for marine protected area planning and marine management. Marine Research Laboratories - Tasmanian Aquaculture and Fisheries Institute, University of Tasmania, Australia.

Barry, J. P., J. M. Grebmeier, J. Smith, and R. B. Dunbar. 2003. Oceanographic versus seafloor-habitat control of benthic megafaunal communities in the S.W. Ross Sea, Antarctica. Pages 327-353 in G. R. Ditullio and R. B. Dunbar, editors. Biogeochemistry of the Ross Sea. American Geophysical Union, Washington, D.C., USA.

Beaman, R. J., and P. T. Harris. 2005. Bioregionalization of the George V Shelf, East Antarctica. Continental Shelf Research 25:1657-1691.

Beaman, R. J., P. E. O'Brien, A. L. Post, and L. De Santis 2011. A new high-resolution bathymetry model for the Terre Adelie and George V continental margin, East Antarctica. Antarctic Science 23:95-103.

Beans, C., J. H. Hecq, P. Koubbi, C. Vallet, S. Wright, and A. Goffart. 2008. A study of the diatom-dominated microplankton summer assemblages in coastal waters from Terre Adélie to the Mertz Glacier, East Antarctica $\left(139^{\circ} \mathrm{E}-145^{\circ} \mathrm{E}\right)$. Polar Biology 31:1101-1117.

Blanchard, J. L., R. F. Heneghan, J. D. Everett, R. Trebilco, and A. J. Richardson. 2017. From bacteria to whales: using functional size spectra to model marine ecosystems. Trends in Ecology and Evolution 32:174-186.

Brandt, A., C. De Broyer, I. De Mesel, K. E. Ellingsen, A. J. Gooday, B. Hilbig, K. Linse, M. R. A. Thomson, and P. A. Tyler. 2007. The biodiversity of the deep Southern Ocean benthos. Philosophical Transactions of the Royal Society B 362:39-66.

Causse, R., et al. 2011. Demersal ichthyofaunal shelf communities from the Dumont d'Urville Sea (East Antarctica). Polar Science 5:272-285.

Clarke, A., R. B. Aronson, J. A. Crame, J. M. Gil, and D. B. Blake. 2004. Evolution and diversity of the benthic fauna of 
the Southern Ocean continental shelf. Antarctic Science 16:559-568.

Constable, A. J., J. Melbourne-Thomas, S. P. Corney, K. R. Arrigo, C. Barbraud, D. K. Barnes, N. L. Bindoff, P. W. Boyd, A. Brandt, and D. P. Costa. 2014. Climate change and Southern Ocean ecosystems I: how changes in physical habitats directly affect marine biota. Global Change Biology 20:3004-3025.

Convey, P., et al. 2014. The spatial structure of Antarctic biodiversity. Ecological Monographs 84:203-244.

Cougnon, E. A., B. K. Galton-Fenzi, A. J. S. Meijers, and B. Legresy. 2013. Modeling interannual dense shelf water export in the region of the Mertz Glacier Tongue (19922007). Journal of Geophysical Research: Oceans 118:5858 5872 .

Dambacher, J. M., D. J. Gaughan, M.-J. Rochet, P. A. Rossignol, and V. M. Trenkel. 2009. Qualitative modelling and indicators of exploited ecosystems. Fish and Fisheries 10:305322.

Dambacher, J. M., H. W. Li, and P. A. Rossignol. 2002. Relevance of community structure in assessing indeterminacy of ecological predictions. Ecology 83:1372-1385.

Dambacher, J. M., P. C. Rothlisberg, and N. R. Loneragan. 2015. Qualitative mathematical models to support ecosystembased management of Australia's Northern Prawn Fishery. Ecological Applications 25:278-298.

Danovaro, R., C. Corinaldesi, G. D’Onghia, B. Galil, C. Gambi, A. J. Gooday, N. Lampadariou, G. M. Luna, C Morigi, and K. Olu. 2010. Deep-sea biodiversity in the Mediterranean Sea: the known, the unknown, and the unknowable. PLoS ONE 5:e11832.

Douglass, L. L., J. Turner, H. S. Grantham, S. Kaiser, A. Constable, R. Nicoll, B. Raymond, A. Post, A. Brandt, and D. Beaver. 2014. A hierarchical classification of benthic biodiversity and assessment of protected areas in the Southern Ocean. PLoS ONE 9:e100551.

Duhamel, G., et al. 2010. Liparids from the Eastern sector of Southern Ocean and first information from molecular studies Cybium 34:319-343.

Dunstan, P. K., S. D. Foster, and R. Darnell. 2011. Model based grouping of species across environmental gradients. Ecological Modelling 222:955-963.

Dunstan, P. K., S. D. Foster, F. K. C. Hui, and D. I. Warton. 2013. Finite mixture of regression modeling for high-dimensional count and biomass data in ecology. Journal of Agricultural, Biological, and Environmental Statistics 18:357375.

Edwards, M., and A. J. Richardson. 2004. Impact of climate change on marine pelagic phenology and trophic mismatch. Nature 430:881.

FAO. 2016. Food and Agriculture Organization of the United Nations (FAO): The EAF-Nansen Programme. http://www.fa o.org/3/a-i6039e.pdf

Foster, S. D., G. H. Givens, G. J. Dornan, P. K. Dunstan, and R. Darnell. 2013. Modelling biological regions from multispecies and environmental data. Environmetrics 24:489 499.

Fulton, E. A. 2010. Approaches to end-to-end ecosystem models. Journal of Marine Systems 81:171-183.

Garcia, S. M., A. Zerbi, G. J. Aliaume, T. Do Chi, and G. Lasserre. 2003. The ecosystem approach to fisheries. Issues, terminology, principles, institutional foundations, implementation and outlook. FAO Fisheries Technical Paper. No. 443. Rome, FAO. $71 \mathrm{p}$

Gaston, G. R. 1987. Benthic polychaeta of the Middle Atlantic Bight: feeding and distribution. Marine Ecology Progress Series 36:251-262.
Gillies, C. L., J. S. Stark, G. J. Johnstone, and S. D. A. Smith. 2013. Establishing a food web model for coastal Antarctic benthic communities: a case study from the Vestfold Hills. Marine Ecology Progress Series 478:27-41.

Gon, O., and P. C. Heemstra. 1990. Fishes of the southern ocean. JLB Smith Institute of Ichthyology, Grahamstown, South Africa.

Griffiths, H. J., A. J. S. Meijers, and T. J. Bracegirdle. 2017. More losers than winners in a century of future Southern Ocean seafloor warming. Nature Climate Change 7:749.

Gurney, G. G., J. Melbourne-Thomas, R. C. Geronimo, P. M. Aliño, and C. R. Johnson. 2013. Modelling coral reef futures to inform management: Can reducing local-scale stressors conserve reefs under climate change? PLoS ONE 8:e80137.

Gutt, J. 2001. On the direct impact of ice on marine benthic communities, a review. Polar Biology 24:553-564.

Gutt, J. 2007. Antarctic macro-zoobenthic communities: a review and an ecological classification. Antarctic Science 19:165-182

Gutt, J., N. Bertler, T. J. Bracegirdle, A. Buschmann, J. Comiso, G. Hosie, E. Isla, I. R. Schloss, C. R. Smith, and J. Tournadre. 2015. The Southern Ocean ecosystem under multiple climate change stresses - an integrated circumpolar assessment. Global Change Biology 21:1434-1453.

Gutt, J., and W. Ekau. 1996. Habitat partitioning of dominant high Antarctic demersal fish in the Weddell Sea and Lazarev Sea. Journal of Experimental Marine Biology and Ecology 206:25-37.

Gutt, J., P. Koubbi, and M. Eléaume. 2007. Mega-epibenthic diversity off Terre Adélie (Antarctica) in relation to disturbance. Polar Biology 30:1323-1329.

Gutt, J., B. I. Sirenko, I. S. Smirnov, and W. E. Arntz. 2004. How many macrozoobenthic species might inhabit the Antarctic shelf? Antarctic Science 16:11-16.

Gutt, J., et al. 2011. Biodiversity change after climate-induced ice-shelf collapse in the Antarctic. Deep-Sea Research Part II: Topical Studies in Oceanography 58:74-83.

Harvey, C. J., J. C. Reum, M. R. Poe, G. D. Williams, and S. J. Kim. 2016. Using conceptual models and qualitative network models to advance integrative assessments of marine ecosystems. Coastal Management 44:486-503.

Heymans, J. J., M. Coll, J. S. Link, S. Mackinson, J. Steenbeek, C. Walters, and V. Christensen. 2016. Best practice in Ecopath with Ecosim food-web models for ecosystem-based management. Ecological Modelling 331:173-184.

Hill, N. A., S. D. Foster, G. Duhamel, D. Welsford, P. Koubbi, C. R. Johnson, and L. Hawkes. 2017. Model-based mapping of assemblages for ecology and conservation management: a case study of demersal fish on the Kerguelen Plateau. Diversity and Distributions 23:1216-1230.

Hoegh-Guldberg, O., and J. F. Bruno. 2010. The impact of climate change on the world's marine ecosystems. Science 328:1523-1528

Hogg, O. T., V. A. Huvenne, H. J. Griffiths, B. Dorschel, and K. Linse. 2016. Landscape mapping at sub-Antarctic South Georgia provides a protocol for underpinning large-scale marine protected areas. Scientific Reports 6:33163.

Hosie, G., P. Koubbi, M. Riddle, C. Ozouf-Costaz, M. Moteki, M. Fukuchi, N. Ameziane, T. Ishimaru, and A. Goffart. 2011. CEAMARC, the collaborative east Antarctic marine census for the census of Antarctic marine life (IPY \# 53): an overview. Polar Science 5:75-87.

Hui, F. K. C., D. I. Warton, S. D. Foster, and P. K. Dunstan. 2013. To mix or not to mix: comparing the predictive 
performance of mixture models vs. separate species distribution models. Ecology 94:1913-1919.

Jansen, J., N. A. Hill, P. K. Dunstan, E. A. Cougnon, B. K. Galton-Fenzi, and C. R. Johnson. 2018a. Mapping Antarctic suspension feeder abundances and seafloor food-availability, and modeling their change after a major glacier calving. Frontiers in Ecology and Evolution 6:94.

Jansen, J., N. A. Hill, P. K. Dunstan, M. P. Eléaume, and C. R. Johnson. 2018b. Taxonomic resolution, functional traits, and the influence of species groupings on mapping Antarctic seafloor biodiversity. Frontiers in Ecology and Evolution 6:81.

Jansen, J., et al. 2018c. Abundance and richness of key Antarctic seafloor fauna correlates with modelled food availability. Nature Ecology and Evolution 2:71-80.

Jones, T. 2017. Commission for the Conservation of Antarctic Marine Living Resources: Vulnerable Marine Ecosystems Registry. www.ccamlr.org/en/document/data/ccamlr-vme-re gistry

Jones, D. O., A. Yool, C. L. Wei, S. A. Henson, H. A. Ruhl, R. A. Watson, and M. Gehlen. 2014. Global reductions in seafloor biomass in response to climate change. Global Change Biology 20:1861-1872.

Jordan, A., M. Lawler, V. Halley, and N. Barrett. 2005. Seabed habitat mapping in the Kent Group of islands and its role in marine protected area planning. Aquatic Conservation: Marine and Freshwater Ecosystems 15:51-70.

Koubbi, P., et al. 2010. Estimating the biodiversity of the East Antarctic shelf and oceanic zone for ecoregionalisation: example of the ichthyofauna of the CEAMARC (Collaborative East Antarctic Marine Census) CAML surveys. Polar Science 4:115-133.

Laufkötter, C., et al. 2015. Drivers and uncertainties of future global marine primary production in marine ecosystem models. Biogeosciences 12:6955-6984.

Levins, R. 1966. The strategy of model building in population biology. American Scientist 54:421-431.

Levins, R. 1993. A response to Orzack and Sober: formal analysis and the fluidity of science. Quarterly Review of Biology 68:547-555.

Lombarte, A., I. Olaso, and A. Bozzano. 2003. Ecomorphological trends in the Artedidraconidae (Pisces: Perciformes: Notothenioidei) of the Weddell Sea. Antarctic Science 15:211-218.

Lutz, M. J., K. Caldeira, R. B. Dunbar, and M. J. Behrenfeld. 2007. Seasonal rhythms of net primary production and particulate organic carbon flux to depth describe the efficiency of biological pump in the global ocean. Journal of Geophysical Research: Oceans 112, C10011.

Marzloff, M. P., L. R. Little, and C. R. Johnson. 2015. Building resilience against climate-driven shifts in a temperate reef system: staying away from context-dependent ecological thresholds. Ecosystems 19:1-15.

Marzloff, M. P., E. C. J. Oliver, N. S. Barrett, N. J. Holbrook, L. James, S. J. Wotherspoon, and C. R. Johnson. 2018. Differential vulnerability to climate change yields novel deepreef communities. Nature Climate Change 8:873-878.

Massom, R., K. Hill, V. Lytle, A. Worby, M. Paget, and I. Allison. 2001. Effects of regional fast-ice and iceberg distributions on the behaviour of the Mertz Glacier polynya, East Antarctica. Annals of Glaciology 33:391398.

Melbourne-Thomas, J., A. Constable, S. Wotherspoon, and B. Raymond. 2013. Testing paradigms of ecosystem change under climate warming in Antarctica. PLoS ONE 8: e55093.
Melbourne-Thomas, J., C. Johnson, P. Alino, R. C. Geronimo, C. Villanoy, and G. Gurney. 2011a. A multi-scale biophysical model to inform regional management of coral reefs in the western Philippines and South China Sea. Environmental Modelling \& Software 26:66-82.

Melbourne-Thomas, J., C. R. Johnson, T. Fung, R. M. Seymour, L. M. Chérubin, J. E. Arias-González, and E. A. Fulton. 2011b. Regional-scale scenario modeling for coral reefs: a decision support tool to inform management of a complex system. Ecological Applications 21:1380-1398.

Melbourne-Thomas, J., S. Wotherspoon, B. Raymond, and A. Constable. 2012. Comprehensive evaluation of model uncertainty in qualitative network analyses. Ecological Monographs 82:505-519.

O'Hara, T. D., A. A. Rowden, and N. J. Bax. 2011. A Southern Hemisphere bathyal fauna is distributed in latitudinal bands. Current Biology 21:226-230.

Orejas, C., J. M. Gili, W. E. Arntz, J. Ros, P. López, N. Teixidó, and P. Filipe. 2000. Benthic suspension feeders, key players in Antarctic marine ecosystems? Contributions to Science $1: 299-311$

Ovaskainen, O., G. Tikhonov, A. Norberg, F. Guillaume Blanchet, L. Duan, D. Dunson, T. Roslin, and N. Abrego. 2017. How to make more out of community data? A conceptual framework and its implementation as models and software. Ecology Letters 20:561-576.

Post, A. L., R. J. Beaman, P. E. O’Brien, M. Eleaume, and M. J. Riddle. 2011. Community structure and benthic habitats across the George V Shelf, East Antarctica: trends through space and time. Deep-Sea Research Part II: Topical Studies in Oceanography 58:105-118.

Post, A. L., P. E. O’Brien, R. J. Beaman, M. J. Riddle, and L. De Santis. 2010. Physical controls on deep water coral communities on the George V Land slope, East Antarctica. Antarctic Science 22:371-378.

Post, A. L., et al. 2014. Chapter 4. Environmental setting. Pages 46-64 in C. De Broyer, et al., editors. Biogeographic Atlas of the Southern Ocean. Scientific Committee on Antarctic Research, Cambridge, UK.

Post, A. L., C. Lavoie, E. W. Domack, A. Leventer, A. Shevenell, and A. D. Fraser. 2017. Environmental drivers of benthic communities and habitat heterogeneity on an East Antarctic shelf. Antarctic Science 29:17-32.

R Core Team. 2016. R: a language and environment for statistical computing. R Foundation for Statistical Computing, Vienna, Austria. www.R-project.org

Raymond, B., J. McInnes, J. M. Dambacher, S. Way, and D. M. Bergstrom. 2011. Qualitative modelling of invasive species eradication on subantarctic Macquarie Island. Journal of Applied Ecology 48:181-191.

Robineau, C., J. Delaplanque-Lasserre, J. Jansen, and M. Eleaume. 2018. Abundances of benthic invertebrate species in the CEAMARC region 2007/08. Australian Antarctic Data Centre.

Sambrotto, R. N., A. Matsuda, R. Vaillancourt, M. Brown, C. Langdon, S. S. Jacobs, and C. Measures. 2003. Summer plankton production and nutrient consumption patterns in the Mertz Glacier Region of East Antarctica. Deep-Sea Research Part II: Topical Studies in Oceanography 50:13931414.

Siegel, D. A., K. O. Buesseler, S. C. Doney, S. F. Sailley, M. J. Behrenfeld, and P. W. Boyd. 2014. Global assessment of ocean carbon export by combining satellite observations and food-web models. Global Biogeochemical Cycles 28:181196. 
Walther, G. R., E. Post, P. Convey, A. Menzel, C. Parmesan, T. J. Beebee, J. M. Fromentin, O. Hoegh-Guldberg, and F. Bairlein. 2002. Ecological responses to recent climate change. Nature 416:389-395.

Woolley, S. N. C., A. W. McCallum, R. Wilson, T. D. O'Hara, P. K. Dunstan, and M. Rouget. 2013. Fathom out: biogeographical subdivision across the Western Australian continental margin - a multispecies modelling approach. Diversity and Distributions 19:1506-1517.

Woolley, S. N. C., D. P. Tittensor, P. K. Dunstan, G. Guillera-Arroita, J. J. Lahoz-Monfort, B. A. Wintle, B. Worm, and T. D. O'Hara. 2016. Deep-sea diversity patterns are shaped by energy availability. Nature 533:393396.

\section{SUPPORTING INFORMATION}

Additional supporting information may be found online at: http://onlinelibrary.wiley.com/doi/10.1002/eap.2065/full 